http://dx.doi.org/10.18675/1981-8106.vol25.n49.p326-339

\title{
A Educação do Campo em Debate: experiências de luta!
}

\author{
Field Education in Debate: experiences of fight!
}

\section{La Educación del Campo en Debate: jexperiencias de lucha!}

\author{
Rafael Rossi \\ Maria Peregrina de Fatima Rotta Furlanetti " \\ 'Universidade Federal do Mato Grosso do Sul (FMS) em Campo Grande, Mato Grosso do Sul - Brasil. \\ E-mail: rafaelrossi6789@hotmail.com \\ "Universidade Estadual Paulista (UNESP), Presidente Prudente, São Paulo - Brasil. E-mail: \\ rotta@fct.unesp.br
}

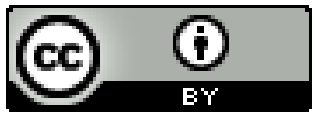

Educação: teoria e prática, Rio Claro, SP, Brasil - eISSN: 1981-8106

Está licenciada sob Licença Creative Common

\section{Resumo}

Neste trabalho problematizamos a educação do campo enquanto potencialidade para uma maior participação das famílias dos educandos/as na organização e cotidiano de escolas em assentamentos rurais. Em muitos casos, padrões educacionais urbanos são reproduzidos acriticamente no território camponês. Assim, a escola se torna um elemento alienado e alienante perante seu contexto espacial e de luta dos assentamentos. Partimos de nossa experiência investigativa com a Escola Educador Paulo Freire localizada no assentamento Rodeio, na cidade de Presidente Bernardes/SP, para problematizar a necessidade de espaços de diálogo como fóruns sobre educação do campo e reuniões coletivas com a comunidade escolar, a fim de que a escola seja, efetivamente, daquela população camponesa, construída e organizada de acordo com as demandas desse local. É nesse sentido que a comunicação e a formação de canais de diálogo para que a comunidade possa se expressar e ter a possibilidade de participar da escola são práticas fundamentais a serem discutidas numa prerrogativa que se baseia numa postura democrática de escola.

Palavras-chave: Educação do Campo; Organização Escolar; Luta; Educação. 


\begin{abstract}
In this paper approached the question the field education as a potentiality for greater participation of the families of students in the organization and daily life of schools in rural settlements. In many cases, urban educational standards are reproduced uncritically on peasant territory. Thus, the school becomes an alienated and alienating element before its spatial context and struggle of the settlements. The work is based in the investigative experience in Paulo Freire' Educator School, located in the settlement Rodeo in the Presidente Bernardes City, in São Paulo State. To discuss the need for dialogue as forums on the field education and collective meetings with the school community, so that the school is effectively that peasant population, built and organized according to the demands of this location and territory. In this sense, communication and the construction of channels that care about dialogue so that the community can express themselves and be able to attend the school, are fundamental issues to be discussed at a prerogative which is based on democratic posture of the school.
\end{abstract}

Keywords: Field Education; School Organization; Struggle; Education.

\title{
Resumen
}

En este trabajo problematizamos la educación del campo en cuanto potencialidad para una mayor participación de las familias de los educandos/as en la organización y cotidiano de escuelas en asentamientos rurales. En muchos casos, patrones educacionales urbanos se reproducen acríticamente en el territorio campesino. Así, la escuela se vuelve un elemento alienado y alienante frente al contexto espacial y de lucha de los asentamientos. Partimos de nuestra experiencia investigativa con la Escuela Educador Paulo Freire, localizada en el asentamiento Rodeio, en la ciudad de Presidente Bernardes/SP, para problematizar la necesidad de espacios de diálogo como fórums sobre educación del campo y reuniones colectivas con la comunidad escolar, a fin de que la escuela de aquella población campesina sea, efectivamente, construida y organizada de acuerdo con las demandas de ese local. Es en este sentido que la comunicación y la formación de canales de diálogo para que la comunidad pueda expresarse y tener la posibilidad de participar de la escuela son prácticas fundamentales a ser discutidas en una prerrogativa que se basa en una postura democrática de escuela.

Palabras clave: Educación del Campo; Organización Escolar; Lucha; Educación.

\section{Introdução}

Este texto representa um esforço para problematizarmos a educação do campo frente aos desafios das escolas localizadas em assentamentos rurais. Partimos da experiência 
desenvolvida na Escola Educador Paulo Freire, localizada no assentamento Rodeio (município de Presidente Bernardes, região oeste do estado de São Paulo), fruto de uma parceria entre o Colegiado de Desenvolvimento Territorial - CODETER - e o Grupo de Estudos e Pesquisa em Educação Popular - GEPEP (vinculado ao Departamento de Educação da UNESP, Faculdade de Ciências e Tecnologia de Presidente Prudente/SP), com a pesquisa, ainda em andamento, intitulada: Projeto Político Pedagógico para Escolas do Campo: Escola Educador Paulo Freire.

Partimos da experiência de pesquisa e refletimos, a partir das contribuições teóricas da educação do campo, os vínculos necessários para um engajamento amplo da comunidade camponesa em suas escolas públicas. Discutir e pesquisar coletivamente a respeito da educação do campo permite ampliarmos nossa compreensão sobre as dificuldades e potencialidades que determinada comunidade escolar apresenta, além de aprofundar o entendimento de contradições e embates que se manifestam em projetos e perspectivas educacionais que envolvam o território camponês. De modo geral, percebemos que os padrões de ensino de escolas localizadas no espaço urbano influenciam e se refletem em escolas localizadas no campo. Isso possibilita afirmar que estão sendo desconsiderados os aspectos pertencentes à cultura camponesa nesses ambientes o que, por sua vez, contribui para uma descaracterização sociocultural que despolitiza a compreensão do campo como produtor também de conhecimentos.

É importante afirmar que toda nossa argumentação sobre a educação do campo se aproxima de um entendimento de luta e resistência que os movimentos sociais desenvolvem na área da educação, em especial, o Movimento dos Trabalhadores Rurais Sem Terra - MST. Dessa maneira, não compartilhamos de uma compreensão de educação presente em muitos discursos de grupos aliados ao modelo de desenvolvimento agrário do agronegócio, em que a preocupação norteadora é a qualificação técnica no manuseio de máquinas e equipamentos em seu dia a dia nas diversas usinas e fazendas inseridas na lógica de concentração fundiária e de renda, onde o processo de mecanização da lavoura já se encontra em estágio avançado. Este tipo de educação tenta adestrar tecnicamente os trabalhadores rurais, disseminando, através da ideologia dominante presente em mídias tendenciosas, a imagem, a máscara e o véu de inclusão educacional e geração de renda; sendo que, na realidade, maximizam em níveis exponenciais a exploração dos camponeses e a sua subordinação. A educação do campo entra em conflito direto com esse posicionamento, já que se baseia na reflexão coletiva e emancipatória dos camponeses.

Dessa forma, para atingir nosso objetivo, dividimos o texto em três partes. Na primeira parte discutimos a educação do campo, enquanto potencialidade para práticas pedagógicas mais coerentes com o contexto camponês e, também, no intuito de explicitar seu aspecto de luta, compreendendo os povos do campo também como produtores de saberes e não através das caricaturas de Jeca, tão disseminadas pelos discursos que embasam a ideologia das classes dominantes. Na segunda apresentamos a Escola Educador Paulo Freire, a fim de compreender seu processo histórico de formação e a urgência em pensarmos ações educativas que levem em consideração a cultura e os interesses dos camponeses. Já a terceira parte se reserva às nossas considerações finais. 
Não pretendemos encerrar, de maneira precipitada e superficial, a discussão da educação do campo e suas escolas. No entanto, pretendemos apontar delineamentos que o envolvimento com a presente pesquisa nos proporcionou e permitiu vislumbrar. Assim sendo, dúvidas, críticas e/ou sugestões são bem-vindas para juntos construirmos, de modo aberto e coletivo, um debate educacional mais comprometido com o ambiente camponês, que resiste secularmente aos ataques de grupos privados de poder que intentam, a todo instante, sua desterritorialização.

\subsection{Educação do Campo: por uma Educação Emancipadora}

Antes de iniciar a discussão, consideramos relevante afirmar, com relação à educação do campo, que estamos nos referindo ao campo do camponês, por isso a escolha do campo e não no campo, visto que o campo se configura como ponto de partida e chegada em nosso entendimento, como nos lembra Fernandes (2006). Assim, investimos na ideia de que as atividades que valorizam a cultura camponesa nos assentamentos, respeitando a diversidade $\mathrm{e}$ trabalhando a partir dos saberes populares, pela ótica da conflitualidade, consiste num caminho promissor a ser seguido como um dos procedimentos metodológicos necessários, para que possamos enriquecer a Pedagogia desenvolvida pelos movimentos socioterritoriais que lutam pela terra, como o Movimento dos Trabalhadores Rurais Sem Terra (MST) e, assim, contribuir para o fortalecimento de ações e reflexões inseridas no Paradigma da Questão Agrária (FERNANDES, 2005).

A desmistificação de ideias é característica de um trabalho pedagógico que se preocupa com a emancipação cidadã de todos envolvidos; a educação, dessa forma, é compreendida como ato de desvencilhamento, a fim de que a libertação possa ser promovida e encarada como possibilidade urgente e totalmente passível de ser concretizada, encontrando na Educação do Campo uma área fértil e convidativa ao estudo dessas temáticas. Por isso, entendemos que a Educação Popular, por meio do ensino de Geografia no processo de alfabetização dos sujeitos de Educação do Campo, se insere na luta pela destruição da ideia de self-made men ${ }^{l}$, bandeira mestra da corrente neoliberal, para dar lugar ao agente coletivo, significando trabalhar para a extinção do individualismo como única saída a uma globalização perversa, como discutida por Santos (2000), para promover ações de desenvolvimento local do coletivo.

Dessa maneira, defendemos ser fundamental investir em ações e práticas metodológicas de pesquisa em assentamentos rurais, que contribuam para diminuir os índices de desestímulos, por parte dos educandos/as, através de atividades culturais que problematizem os conflitos inerentes ao contexto da educação do campo, para que possamos enriquecer os conteúdos discutidos em sala de aula, pautados no (re) conhecimento de seus jovens.

\footnotetext{
${ }^{1}$ A ideia de self-made-men ou homem que se faz sozinho é uma expressão que ajuda a refletirmos sobre os discursos neoliberais que intentam, constantemente, nos convencer de que basta trabalhar duro e sem se mobilizar que todos teremos sucesso na vida.
} 
Esse posicionamento é importante, pois ao trabalhar com os conflitos, a partir de uma leitura geográfica, o território aparece como elemento central: em sua disputa pelos movimentos socioterritoriais que lutam pela Reforma Agrária (em que também está presente a luta pelo acesso à educação) e o agronegócio empreendido pela lógica de concentração fundiária e de renda. O primeiro se territorializa no campo como estratégia de luta, combate e resistência a uma lógica que pretende sua aniquilação e a homogeneização do campo, enquanto o segundo defende a monocultura, a exploração do trabalhador rural, o uso massivo de agrotóxicos, a exploração dos recursos naturais etc. Queremos dizer: o território do campo aparece como disputa e conflito e, também, como uma lógica de territorialização de práticas libertárias e democráticas a partir do embate empreendido pelos movimentos socioterritoriais como o MST.

Concordamos com Fernandes (2005b), quando entende que a questão agrária se relaciona diretamente aos conflitos pela terra. Porém, analisá-la somente por esse viés constitui uma visão parcial. Isso ocorre uma vez que tais conflitos não se manifestam somente na etapa de enfrentamento entre camponeses e Estado. Essa perspectiva nos remete à reflexão sobre a Educação do Campo.

Sendo assim, compreendemos que os conflitos também ocorrem uma vez que as políticas para essa modalidade de ensino, em muitos casos, não respeitam e não se preocupam em conhecer a realidade na qual se inserem.

A conflitualidade é o processo de enfretamento perene que explicita o paradoxo das contradições e as desigualdades do sistema capitalista, evidenciando a necessidade do debate permanente, nos planos teóricos e práticos, a respeito do controle político e de modelos de desenvolvimento [...] A conflitualidade é inerente ao processo de formação do capitalismo e do campesinato. Ela acontece por causa da contradição criada pela destruição, criação e recriação simultâneas dessas relações sociais. A conflitualidade é inerente ao processo de formação do capitalismo e do campesinato por causa do paradoxo gerado pela contradição estrutural. A conflitualidade e o desenvolvimento acontecem simultâneos e consequentemente, promovendo a transformação de territórios, modificando paisagens, criando comunidades, empresas, municípios, mudando sistemas agrários e bases técnicas, complementando mercados, refazendo costumes e culturas, reinventando modos de vida, reeditando permanentemente o mapa da geografia agrária, reelaborado por diferentes modelos de desenvolvimento. A agricultura camponesa estabelecida ou que se estabelece por meio de ocupações de terra e implantação de assentamentos rurais, resultantes de políticas de reforma agrária, promovem conflitos e desenvolvimento. A agricultura capitalista, na nova denominação de agronegócio, se territorializa, expropriando o campesinato, promovendo conflito e desenvolvimento. É importante destacar, ainda, que uma parte fundante desse paradoxo é a obsessão da destruição do campesinato e no crescimento da organização camponesa em diferentes escalas e de diversas formas: no Brasil, na América Latina e no Mundo. (FERNANDES, 2005, p.5-6) 
O trecho de Fernandes (2005) ajuda-nos a entender a importância de problematizar a conflitualidade, que, em nosso parecer, contribui no desenvolvimento de atividades pedagógicas rumo a uma real educação do campo. O conflito é elemento estruturante à discussão da questão agrária e optar por não inseri-lo nessa modalidade de ensino implica em não (re)conhecer o campo como território em que moram e trabalham os camponeses e, muito menos, se preocupar em conhecer seus jovens para aumentar o incentivo e estímulo à educação.

Roseli Salete Caldart, em toda sua obra, porém, em específico nos seus escritos Pedagogia do Movimento Sem Terra (2004a), Movimento Sem Terra: lições de Pedagogia (2003) e Elementos para construção do Projeto Político e Pedagógico da Educação do Campo (2004b) - nos fornece subsídios para problematizar a educação no campo, para o campo e do campo. Estimula, inclusive, a problematização da conflitualidade e do compromisso ao se assumir a tarefa pedagógica em lidar cotidianamente com essa modalidade de ensino.

Percebemos o senso de construção e permanência da coletividade nessa pedagogia da práxis (teoria e prática combinadas) que o MST, ao longo de sua história, põe em movimento. A identidade coletiva, apontada pela autora, possui uma significância imprescindível de ser trabalhada e discutida. Isso, em razão do destaque que ganha o processo educativo na luta pela Reforma Agrária. Tais processos se manifestam, já que esse movimento socioterritorial aprendeu em sua formação o valor e a importância da união. Essa identidade Sem Terra, em nosso entendimento, está intimamente ligada com ser do campo, daí a necessidade em explicitar os conflitos envolvidos na questão agrária articulando-os aos conflitos e contradições inerentes ao modo de produção capitalista: para avançar rumo a uma educação do campo, com os jovens no campo se identificando com ser do campo.

Dizer que o MST enraíza os sem-terra significa afirmar que ele proporciona a essas pessoas a condição de vincular-se novamente a um passado e a uma possibilidade de futuro, que lhes permite desenvolver-se como seres morais, intelectuais, espirituais e, poderíamos acrescentar, culturais. Enquanto trabalhadores da terra de quem foi tirada a terra, ou a possibilidade social de tê-la como objeto de seu trabalho, os sem-terra foram desenraizados e, portanto, diminuídos em sua condição humana [...] Escolheram lutar pelo seu próprio enraizamento: ocuparam a terra que lhes devolveria uma boa parte de suas raízes (CALDART, 2004 a, p. 99).

O trecho em questão é emblemático sob, pelo menos, dois sentidos. A autora chama a atenção para o caráter de projeto que o pertencimento a esse movimento socioterritorial proporciona aos seus membros. Outro aspecto diz respeito às manifestações por meio das ocupações de terra. É importante que atentemos a esses dois pontos, em razão do forte caráter educativo presente em tais práticas. Se, por um lado, as ocupações representam uma 
manifestação coletiva pacífica do movimento, onde a vontade é se fazer ouvir e ser inserido no círculo comumente hermético de elaboração das políticas públicas da reforma agrária; por outro lado, essa prática é, justamente, um dos condicionantes necessários que promovem a construção da identidade Sem Terra. Significando que ações empreendidas com um objetivo partilhado de maneira comum, baseado em um projeto societário com justiça social àqueles que foram compulsoriamente expulsos do campo, contribui, de maneira relevante, ao processo educativo emancipatório que, por meio da análise vivida e refletida do processo de conflitualidade no campo, almeja patamares democráticos mais efetivos e menos efêmeros.

Nesse sentido, o pensamento de Roseli Salete Caldart ajuda na compreensão e debate por uma educação do campo. Pensar essa modalidade de ensino significa pensar os conflitos imanentes e estruturais do modo capitalista de produção, ou seja, significa questionar, desconstruir, propor e lutar em um caminho onde a esperança do respeito à dignidade de centenas de homens e mulheres, crianças, jovens e idosos se faça totalmente plausível, urgente e necessária. Os escritos da autora, aqui em debate, contribuem para o entendimento dos desafios às políticas públicas de educação do campo, aceitando e respeitando as famílias de trabalhadores que lá residem e possuem vínculos históricos com esse território.

Vale ressaltar que o conceito de território é de fundamental importância nessa discussão. O campo deve ser respeitado e encarado como território de vários sujeitos, com seu direito constitucional à educação que contemple, respeite e - para nós - valorize seus conhecimentos, culturas e tradições. Daí também a ligação intrínseca entre a educação popular e a educação do campo, visto que ambas representam anseios contra-hegemônicos de resistência. Luta-se para resistir ao processo de homogeneização posto em movimento crescente pela atual globalização como perversidade (SANTOS, 2000). Teoricamente, essa luta e resistência também convida à reflexão por procedimentos metodológicos capazes de analisar tais políticas públicas em seu processo de implementação e elaboração nas diferentes regiões do país, invitando, também, à promoção de discussões que contemplem essa modalidade de ensino em seu processo de territorialização, ou seja, em seu fluxo materializado onde, mais uma vez, os conflitos tornam-se presentes, fazendo-se necessário que sejam desvendados, explicitados.

É necessário, relativo às escolas que assumem o compromisso de ser do campo, o engajamento coletivo de todos os envolvidos, como fruto de um processo histórico permeado por lutas e conflitos pela garantia de uma educação que se coadune à população que mora no campo e vem sendo, ao longo do tempo, vista pelas políticas educacionais burguesas como sinônimo de atraso e ignorância. Os paradigmas teóricos educacionais, que apenas servem para engessar e burocratizar a educação do campo, devem ser superados, abrindo espaço a novas metodologias que busquem contribuir para o pensar certo e coerente, principiado da práxis.

O projeto político e pedagógico da educação do campo se insere nesse contexto de conflitos. Conflitos, estes, de lutas sociais por direitos e pela preservação de mecanismos autônomos e de autogestão dos diferentes e múltiplos territórios que vivenciam cotidianamente a exclusão social em suas várias dimensões. Faz-se necessário incorporar tais 
conflitos como aporte para problematizações dos entraves e das desigualdades sociais produzidas nas diversas escalas, sejam elas nacionais, estaduais ou municipais. A luta se mostra importante a partir das conquistas obtidas, como é o caso da aprovação das Diretrizes Operacionais para Educação Básica nas Escolas do Campo (Parecer no 36/2001 e Resolução no1/2002 do Conselho Nacional de Educação), de acordo com Caldart (2004b).

Dessa forma, podemos perceber que a educação do campo permite que não nos esqueçamos do passado de lutas e conflitos que originaram muitas escolas. Além disso, também é importante perceber que a educação do campo trabalha e defende um preceito de gestão e organização escolar de modo aberto e democrático. Isso, por sua vez, é fundamental para que pais, educandos/as, funcionários e gestores debatam em pé de igualdade a escola que estão produzindo. Sendo assim, a seção seguinte aborda um detalhamento da Escola Educador Paulo Freire, defendendo a inserção na pauta de discussões com esses dois preceitos da educação do campo: a gestão participativa e o planejamento escolar que aprende com seu passado.

\subsection{Quando escola também aprende...}

Tardif e Lessard (2011) argumentam que a escola não se conforma e também não deve ser compreendida somente enquanto espaço físico, mas, sim, em um espaço social encarado como lugar de interações entre os indivíduos que interferem nesse ambiente educacional. Esses autores contribuem para pensarmos a escola enquanto espaço social atrelado também ao seu contexto, ao seu entorno. Isso se justifica, já que entendemos que uma educação que trabalhe com preceitos e preocupações que visem à construção da autonomia e de uma visão crítica sobre a realidade junto a seus educandos/as, não deve se fechar a questões e temáticas relacionadas ao lugar e ao contexto social em que se encontra.

Dessa forma, podemos questionar: refletir e trabalhar em uma escola localizada no campo é o mesmo que desempenhar essas funções em uma escola no espaço urbano? Como se dá a organização escolar de um ambiente educacional do campo que não trabalha com preceitos da Educação do Campo? Qual a importância e influência da participação de pais, funcionários e famílias residentes no campo em suas escolas? Quais os limites e potencialidades da Educação do Campo no debate sobre a organização escolar? Tais questionamentos se justificam, já que inferimos a hipótese de que os padrões de organização escolar urbanos influenciam e também são aplicados, acriticamente, na organização e estruturação de muitas escolas localizadas no campo.

Dentro das diferentes práticas da educação, podemos identificar o papel que desempenha a Educação do Campo enquanto uma possibilidade de inserir ações e reflexões da realidade do campo, novas perspectivas sobre o futuro e, fundamentalmente, a produção de uma nova consciência sobre sua realidade e as questões que elencamos no parágrafo anterior, pois, conforme nos esclarece Freire (1981, p.95): "Não há conscientização popular sem uma radical denúncia das estruturas de dominação e sem o anúncio de uma nova realidade a ser criada em função dos interesses das classes sociais hoje dominadas". 
Esse alerta destacado por Freire (1981) é levado em consideração nesse projeto, já que pesquisamos o ambiente educacional em seu processo de organização e funcionamento no âmbito da Escola Educador Paulo Freire, localizada no assentamento Rodeio no município de Presidente Bernardes/SP. O município se localiza na $10^{a}$ Região Administrativa do Estado de São Paulo, conhecida como Pontal do Paranapanema, a qual, segundo Leite (1999), teve seu processo de ocupação baseado na grilagem de terras por grandes fazendeiros. A escola, alvo de nossa pesquisa, localiza-se, portanto, no campo, e enfrenta, na atualidade, graves desafios, estando, inclusive, sob o risco de ser fechada.

Acreditamos que a assertiva de Kolling, Cerioli e Caldart (2002) nos ajuda no desvendar desse processo de entendimento sobre o potencial da educação do campo. Esses autores afirmam que falar sobre esse tipo de educação, não implica somente em pensar uma escola marginalizada e idealizada por padrões elitizados do Estado para os camponeses. Tratase, justamente, do esforço no sentido contrário, ou seja, é preciso ter consciência de que se trata de uma escola no e do campo. Uma escola que respeite e leve sempre em consideração a dimensão política da luta pela Reforma Agrária e que esteja pedagogicamente atenta à cultura campesina, sendo "enraizada também na práxis da Educação Popular e da Pedagogia do Oprimido" (KOLLING; CERIOLI; CALDART, 2002, p.13).

A Escola Educador Paulo Freire foi inaugurada em 04 de fevereiro de 2004, e oferece o ensino infantil e fundamental. Fruto de um processo de luta e reivindicação dos assentamentos, a escola contou com a participação das famílias dos educandos/as para sua construção, pois, antes de sua implantação, as crianças tinham que se deslocar $30 \mathrm{~km}$ para frequentar outra escola localizada em Nova Pátria (distrito de Presidente Bernardes/SP). Em seu período inicial de atividades, no ano de 2004, a escola contava com aproximadamente 100 educandos/as matriculados, e, em 2012, as matrículas perfazem 52 educandos, o que implica em uma defasagem de $48 \%$. Tal situação se dá em decorrência de um processo de construção da organização escolar, com inúmeros elementos e fatores que se articulam nessa dinâmica. Neste artigo, focamos alguns desses aspectos, os que mais chamam a atenção.

Em primeiro lugar, pode-se perceber uma perda da presença coletiva comunitária na escola e, inclusive, na vida da comunidade do assentamento. No início do funcionamento das atividades escolares uma série de eventos e práticas coletivas aconteciam de modo participativo e engajado, tais como: casamentos e festas comemorativas do assentamento realizadas no espaço escolar, corroborando para um envolvimento das famílias dos alunos no desenvolvimento da cultura popular e, também, no processo de interação social com a escola. Também podemos citar, no rol das perdas sofridas pela escola, o abandono da horta comunitária, um projeto que envolvia diretamente pais, alunos, funcionários, enfim, todos os agentes que contribuem na construção da organização escolar. Perda, esta, que, por sua vez, contribui negativamente para uma arquitetura escolar desconectada de seu contexto social, o que pode ser evidenciado com os muros que rodeiam a escola, em uma conotação explícita de que não está aberta ao coletivo.

No que se refere às práticas pedagógicas desenvolvidas entre os agentes que trabalham na escola, podemos trazer ao debate a questão do Projeto Político Pedagógico (PPP). A 
escola, até os dias de hoje, em 2015, não conseguiu estruturar coletivamente seu PPP, implicando uma série de dificuldades do ponto de vista das orientações das atividades e do entendimento mais geral sobre educação e formação que se pretende debater e defender nos interesses do território camponês.

Essa escola não possui um coordenador/a pedagógico que auxilie no desenvolvimento do trabalho de professores e na aprendizagem escolar dos alunos. Isso pode acarretar uma desconexão da dinâmica em que se perpassa a organização da escola, no sentido em que esta não possui um vínculo eficaz e fortalecido entre seus agentes, isto é, não há uma ligação direta e profícua entre as dificuldades e problemas enfrentados pelos professores e também pelos alunos, assim como não existem espaços para se debater e refletir sobre tais temáticas.

No início do funcionamento da escola, esta se encontrava aberta à comunidade nos períodos da manhã, tarde e à noite, inclusive durante finais de semana. Hoje em dia, todas as atividades da escola somente ocorrem durante a manhã. Além disso, o HTPC (Horário de Trabalho Pedagógico Coletivo) não ocorre de modo periódico, sistemático e que debata todos os problemas e dificuldades que elencamos até aqui.

A maioria dos atuais funcionários da escola não são moradores do assentamento. No entanto, não estamos argumentando no sentido de que somente aqueles que pertencem ao assentamento devem trabalhar na referida escola. Porém, é preciso estar atentos ao contexto social em que esse ambiente educacional está localizado, sobretudo ao observar um conjunto de problemas de ordem pedagógica e de relacionamento com a comunidade escolar.

O que podemos perceber, na atualidade, é que a escola deixou de proporcionar a criação desses espaços de envolvimento da comunidade, haja vista que, ao passar por oito anos de trabalhos escolares, verifica-se um conjunto de problemas e desafios a serem superados e que abordamos anteriormente.

Os aspectos acima expostos evidenciam a necessidade do debate da gestão escolar, entendida como elemento articulador dos "objetivos mais amplos da instituição, relacionados ao compromisso com a conservação e transformação social” (LIBÂNEO, p. 325, 2008). Ao passo que, ao analisarmos a existência da Escola no assentamento, podemos perceber que esse espaço articulador de possibilidades pode ser levado a perspectivas de mudanças, ao mesmo tempo em que pode se manifestar enquanto espaço articulador e de manutenção ou permanência de formas conservadoras de gestão escolar, conforme diz Libâneo (2008):

Considerando os objetivos sociopolíticos da ação dos educadores voltados para as lutas pela transformação social e da ação da própria escola de promover a apropriação do saber para a instrumentação científica e cultural da população, é possível não só resistir às formas conservadores de organização e gestão escolar, como também adotar formas alternativas, criativas, que contribuam para uma escola democrática a serviço da formação de cidadãos críticos e participativos e da transformação das relações sociais presentes (LIBÂNEO, 2008, p. 328). 
Nesse sentido, é fundamental a presença e participação da comunidade na escola, preceito, este, que a educação do campo pode contribuir. Essa participação é entendida enquanto espaço de debates e construção de propostas que possam impulsionar o avanço dos objetivos propostos pela escola, conforme nos esclarece Libâneo (2008):

\begin{abstract}
A participação é o principal meio de assegurar a gestão democrática, possibilitando o envolvimento de todos os integrantes da escola no processo de tomada de decisões e no funcionamento da organização escolar. A participação proporciona melhor conhecimento dos objetivos e das metas da escola, de sua estrutura organizacional e de sua dinâmica, de suas relações com a comunidade, e propicia um clima de trabalho favorável a maior aproximação entre professores, alunos e pais (p. 328).
\end{abstract}

Assim, perante todas essas dificuldades, em 26 de Setembro de 2011 foi realizado o I Fórum Microrregional de Educação e Cultura do Campo, a partir de uma articulação feita pela Colegiado de Desenvolvimento Territorial - CODETER. Tal fórum teve como objetivo colocar em pauta de discussão a educação do campo nas escolas do Oeste Paulista. Durante esse evento, apareceram as questões elencadas anteriormente a respeito dos problemas enfrentados pela Escola Educador Paulo Freire. Desde final de 2011, até o início de janeiro de 2013, ocorreram seis reuniões com os pais dos educandos/as nas dependências escolares.

Como resultado dessas reuniões podemos apontar três pontos fundamentais para construção de um ambiente escolar que também está disposto a aprender. Um primeiro ponto refere-se à conscientização das famílias da necessidade de levar em consideração a educação do campo como forma para despertar a importância sobre a participação da comunidade dos assentamentos na escola. Outro elemento importante, obtido a partir do debate em tais reuniões, diz respeito ao fato de a comunidade apontar a relevância de professores com formação em educação do campo, como meio para se desenvolver práticas pedagógicas mais condizentes com o território em que a escola se localiza. Por fim, podemos elencar o aumento de matrículas nessa escola, incluindo crianças que saíram e agora estão retornando, bem como seus pais estão participando de modo mais ativo na vida escolar.

Portanto, não se trata de considerar a educação do campo como a salvadora da pátria, como sendo capaz de resolver todos os problemas e obstáculos. No entanto, acreditamos que estudar esse tipo de educação e, no caso analisado, nos atentarmos para o caráter de luta, reivindicação e resistência que os trabalhadores do campo desempenharam na construção da escola Paulo Freire. Também é urgente e necessário lembrarmos que a educação do campo trabalha com uma dinâmica de participação e gestão coletiva. Dessa maneira, a partir da experiência aqui em debate, afirmamos que enquanto as decisões sobre a escola forem elaboradas e executadas por uma gestão hermética, não caminharemos para patamares educacionais mais inclusivos. O que a escola Paulo Freire vem aprendendo é que, no debate aberto e comunitário, todos podem opinar e ser ouvidos, pois rompe-se com uma 
compreensão preconceituosa e arrogante, que considera camponeses como ignorantes e atrasados. Quando as famílias dispõem de espaço e oportunidade para se expressarem, a escola aprende e cresce junto, de forma democrática e consciente.

\subsection{Considerações Finais}

Do ponto de vista da pesquisa acadêmica educacional, a educação do campo também se mostra uma área fértil de investigação e de requalificação de procedimentos metodológicos. Mais uma vez, a ideia de conflito aparece pertinente à discussão pela proposição de análise pelo confronto, pela disputa. Lembramos a afirmação de Bourdieu (1997) quando aponta a necessidade de incorporação do confronto na análise metodológica, incorporando, também, a análise dialética da realidade. Assim sendo, partindo de procedimentos que se inserem no cotidiano do campo, como aporte para pensar junto ao pensamento de Caldart (2004a) e Caldart (2004b) uma educação condizente com os interesses dos camponeses, sejam eles socioculturais, econômicos ou de qualquer outra ordem, pois, dessa maneira, o pesquisador - pela proximidade física com os camponeses - não deve reduzilos a mero objeto estatístico de pesquisa. Na contramão desse raciocínio, os camponeses devem ser, para os pesquisadores em educação do campo, participantes ativos da construção de uma metodologia preocupada com a transformação, com maiores níveis de democratização do ensino e com uma maior efetividade das políticas públicas de educação do e no campo.

Portanto, concordamos com a urgência em articular mobilizações sociais com a parceria das instituições públicas de ensino superior para pensar políticas públicas regionais de educação do campo e seu currículo condizente, como resgate de uma dívida do estado brasileiro com a população do campo pensada, desde o início do século XX, como sinônimo de atraso e ignorância pela agenda burguesa. Nesse aspecto, como ampliar os procedimentos metodológicos de pesquisa junto a educação do campo? Como problematizar em escala nacional uma articulação que mobilize a elaboração de políticas educacionais e currículos mais democráticos e condizentes com a realidade do campo? Essas questões são importantes para, coletivamente, avançarmos na luta por uma educação do campo.

A educação do campo não se configura em uma marca, título ou selo que determinada comunidade escolar adquire, passando a utilizar determinado "pacote tecnológico/didático". Ela precisa ser compreendida enquanto um processo, ou seja, há escolas e comunidades que assumem o compromisso da educação do campo e outras que ainda se baseiam na educação rural ou para o campo, sem discutir as conflitualidades da questão agrária e suas repercussões na dimensão educativa.

Problematizar a educação do campo em escolas localizadas em assentamentos rurais é trabalhar e refletir rumo a uma gestão participativa e coletiva, em que as famílias dos educandos/as não sejam excluídas das decisões gerenciadas pela diretoria escolar. Também é preciso considerar que, no caso da escola aqui analisada, sua construção partiu de um processo de luta e reivindicação, ou seja, não podemos permitir que a atual gestão escolar 
menospreze esse fato e passe por cima da opinião de vários assentados que lutam também pelo seu direito à educação.

O território camponês também se insere em conflito educacional: uma educação meramente de qualificação técnica para a subordinação do camponês na lógica de acumulação de terra e capital do agronegócio em contraste com uma educação do campo, que nasce da terra, dos saberes e da cultura camponesa, que resiste aos ataques e ofensivas do desenvolvimento do capitalismo, para se preocupar com a emancipação humana, com a formação coletiva. Assim, precisamos desmistificar discursos e desenvolver procedimentos metodológicos de investigação científica que permitam compreender, de modo mais profundo, tais conflitos, a fim de que as escolas do campo não se tornem alienadas e alienantes em seu próprio território.

\section{Referências}

CALDART, R. S. Pedagogia do Movimento Sem Terra. São Paulo: Expressão Popular, 2004a.

CALDART, R. S. Elementos para construção do Projeto Político e Pedagógico da Educação do Campo. In: MOLINA, M. C.; JESUS, S. M. S. A. Educação do Campo: Contribuições para a construção de um Projeto de Educação do Campo. Brasília: Zenaide, 2004b. p. 10-31.

FERNANDES, B. M. Os campos da pesquisa em educação do campo: espaço e território como categorias essenciais. A pesquisa em Educação do Campo, v. XX, p. 10-21, 2006.

FERNANDES, B. M. Questão Agrária: conflitualidade e desenvolvimento territorial. Revista Nera, Presidente Prudente/SP, v.7, n.7, p.1-57, 2005.

FREIRE, P. Ação Cultural para Liberdade e outros escritos. 5ed. Rio de Janeiro: Ed. Paz e Terra, 1981.

KOLlinG, E. J.; CERIOLI, P. R.; CALDART, R. S. Educação do campo: identidade e políticas públicas. Brasília: Zenaide, 2002. (Coleção Por uma Educação Básica do Campo, n.4).

LEITE, S. C. Escola rural: urbanização e políticas educacionais. São Paulo: Cortez, 1999.

LIBÂNEO, J. C. Educação escolar: políticas, estruturas e organização. 6ed. São Paulo: Cortez, 2008.

SANTOS, M. Por uma outra globalização - do pensamento único à consciência global. São Paulo: Record, 2000. 
TARDIF, M.; LESSARD, C. O trabalho docente - Elementos para uma teoria da docência como profissão de interações humanas. 6ed. Rio de Janeiro: Petrópolis, 2011.

Recebido em: 04/03/2013

$1^{a}$ revisão: $26 / 09 / 2013$

$2^{\mathrm{a}}$ revisão: 04/05/2015

Aprovado para publicação em: 07/05/2015

Publicado em: 31/08/2015 